severe pre-eclampsia may occur early enough to retard fetal growth. It is therefore important to distinguish between pre-eclampsia and eclampsia in such comparisons.

The relatively small percentage of Yoruba primigravidae who are over 25 years of age tend to be overweight and to show a higher than average incidence of pre-eclampsia during pregnancy of the type seen in Europe. These women are usually in nonmanual occupations. There is good evidence that hypertension is common in Yoruba women in middle life.-I am, etc.,

M.R.C. Medical Sociology Unit,

DUGALD BAIRD Centre for Social Studies, Aberdeen

1 Thompson, B., and Baird, D., fournal of Obstetrics and Gynaecology of the British Com-

\section{Subclinical Brucellosis}

SIR-To advise in a short article on brucellosis (31 March, p. 791) that the term "subclinical" should be used with care does not mean that it should be used rarely or even reluctantly-provided there is no doubtbut I apologize to Dr. R. J. Henderson (5 May, p. 306) if I failed to express myself clearly. I wonder, however, how many clinicians would agree that in practice subclinical brucellosis is always a perfectly obvious state. Continuing ill health in brucellosis is not always immediately apparent and thus a paragraph on chronic brucellosis later in the same article is partly an apologia for some of my own imperfections.

The term "subclinical" should not be used merely because antibody tests remain positive after recovery, and neither does it seem fair if during an earlier acute illness, however mild, the diagnosis was not considered. During Dr. Henderson's 1966-7 inquiry ${ }^{1}$ many persons, among them 50 veterinary surgeons, were visited and interviewed and their histories were recorded. If these subjects were not also examined, for a few the description "subclinical" may not have been appropriate. Seven of 70 veterinary surgeons in a comparable survey in southwest Wales had splenomegaly, an abnormal clinical sign', and in one who was symptomfree liver biopsy showed cirrhosis with heavy iron deposition, an indication for repeated venesection. Brucellosis was possibly a contributory factor, in which case the deceptive term "subclinical" would hardly apply. But for the great majority of veterinary surgeons who, despite the laboratory findings, are well, why another label? - I am, etc.,

EIRIAN WIILIAMS Pembroke County War Memorial Hospital, Haverfordwest, Pembs

1 Henderson, R. J., Lancet, 1967, 2, 353. 2 Williams, B., Veterinary Matters, 1972, pt. 5, p. 2.

\section{Use of Naloxone in Opiate Poisoning}

Str,-In their letter Drs. R. A. Tarala and J. A. H. Forrest (2 June, p. 550) describe the treatment of dextropropoxyphene poisoning with naloxone.

Other cases of poisoning with dextropropoxyphene have also been successfully treated with naloxone, ${ }^{1}$ which has considerable advantages over the currently used opiate antagonists. It is a potent antagonist which, unlike the other antagonists, has no respiratory or circulatory depressant action, even in patients deeply unconscious from non-opiate drug poisoning. ${ }^{2}$ This allows naloxone to be given safely to unconscious patients where the diagnosis of opiate poisoning is suspected but not confirmed. In addition, naloxone has a high safety margin, having been given in large doses with no toxicity, ${ }^{3}$ it is effective in the treatment of pentazocine poisoning, ${ }^{2}$ it has no addiction potential,4 and produces no psychotomimetic effects. ${ }^{5}$

Naloxone, when available, should be regarded as the treatment of choice in all opiate poisonings, and in view of its proved qualities I hope that it will soon be made available for general use in Britain.-I am, etc.

Royal Victoria Infirmary,

L. E. J. Evans Newcastle upon Tyne

1 Kersh, E. S., Chest, 1973, 63, 112.

2 Evans, L. E. J., Roscoe, P., Swainson, C. P., and Prescott, L. F., Lancet, 1973, 1, 452.

Zaks, A., Fink, M., and Freedman, A. M., in Committee on Problems of Drug Dependence 31st Meeting, Palo Alto, 1969.

Jasinski, D. R., Martin, $\mathbf{W}$. R., and Haertzen, mental Therapeutics, 1967, 157. 420 .

Hasbrouck, J. D., Anesthesia and Analgesia Current Researches, 1971, 50, 954.

\section{Poisoning by Dry-cleaning Fluid}

SIR, - We recently treated a small child who had drunk dry-cleaning fluid in a launderette. Apparently this liquid was left in a beaker on a low table so that customers could remove spots before general cleaning. The main supply was kept nearby in a lemonade bottle.

I do not know how widespread this practice is, but it is manifestly an extremely dangerous one in areas where there are liable to be many people with young children.I am, etc.

Cynthin M. IlLINGWORTH

Children's Hospital

Shefiield

\section{Doctors and Overpopulation}

SIR,-I would like to make a personal comment on the thoughtful letter from Dr. F. Difford (12 May, p. 369). Perhaps for the benefit of readers who are not familiar with the Doctors and Overpopulation Group I can include a summary of our aims?

These are: (1)-To exhort the Government to admit that a population problem exists in this country. (2)-To press for a large extension of family planning services, emphasizing that such facilities must be provided free of charge within the framework of the N.H.S. (3)-To endeavour to ensure that the abortion law remains liberal and that more facilities be available under the N.H.S. (4)-To see that the facilities for male and female sterilization be massively increased and made available under the N.H.S. (5)-To urge a reappraisal of the laws and policies that govern the employment of women in society with a view to bringing abourt a significant improvement in their career prospects. (6)-To be in the vanguard of a nation-wide campaign of population education.

Dr. Difford objects to the third of these and particularly in the context of population control. Everybody I am sure agrees that prevention is infinitely preferable to the termination of an unwanted pregnancy. It is for this reason that we regard an efficient contraceptive service backed up by education as of the greatest importance. However, even the best contraceptives when used efficiently do have a failure rate. Given this and human fallibility, it would seem that in the foreseeable future there is likely to be a need for termination of pregnancy.-I am, etc.,

London N.10

GEORGE MORRIS Secretary,

\section{Clinical Work in Public Health}

SIR,-The Public Health Committee would wish it to be generally known that in April of this year they established a working party "to review as a matter of urgency, and in depth, the role, organization, training, grading structure, and future functions of those doctors currently unidertaking clinical work in the public health field who will all be transferred to the reorganized health services." The members of the working party, in addition to myself, are: Dr. Catherine Atkins (a principal medical officer), Dr. Athene Baldwin (a clinical medical officer on the upper salary range), Dr. Rosemary Graham (a principal medical officer), Dr. Mary Patricia Jenkins (a clinical medical officer on the upper salary range), Dr. $R$. Mayon-White (a consultant paediatrician), Dr. Maud Menzies (a principal medical officer), Dr. A. Reeves (a general practitioner) and Dr. H. G. Robinson (a deputy medical officer of health).

The working party concluded that it should first identify the range of work carried out by clinical public health doctors at the present time and move from there to a consideration of the future. The major part of this operation will be to produce a concept or concepts of the longer-term future of this group of doctors. In the light of the collective experience of the members it has already made considerable headway with these tasks, but it recognizes that there may be other individuals with special experience who may wish to draw attention to facets of the matter which they believe might not otherwise occur to members of the working party. If this is so, then my colleagues and I would be delighted to receive such observations, which should be sent to B.M.A House, Tavistock Square, London, WC1H 9JP.-I am, etc.,

C. D. L. Lycett

B.M.A. House,

Chairmen, Public Health

\section{Distinction Awards}

SIR,-The decision of the Annual Representative Meeting calling for renegotiation of the distinction award scheme (Supplement, 16 June, p. 117) gives the profession an opportunity to take a fresh look at methods of remunerating consultants in the light of the attack on private practice. The growth of private practice is an indicator of unmet needs in the National Health Service and we would do well to consider how the privileges sought by private patients can be offered to all. Patients seek private artention to ob-ain more time, privacy, and consideration than a consultant can offer in a busy outpatient 